\title{
pH-Triggered Adhesiveness and Cohesiveness of Chondroitin Sulfate-Catechol Biopolymer for Biomedical Applications
}

\author{
Annachiara Scalzone ${ }^{1}$, Maria A. Bonifacio ${ }^{2}$, Stefania Cometa ${ }^{3}$, Fabio Cucinotta ${ }^{4}$, \\ Elvira De Giglio ${ }^{2}$, Ana M. Ferreira ${ }^{1 * t}$ and Piergiorgio Gentile ${ }^{1 * t}$
}

${ }^{1}$ School of Engineering, Newcastle University, Newcastle upon Tyne, United Kingdom, ${ }^{2}$ Department of Chemistry, University of Bari Aldo Moro, Bari, Italy, ${ }^{3}$ Jaber Innovation s.r.l., Rome, Italy, ${ }^{4}$ School of Natural and Environmental Sciences,

Newcastle University, Newcastle upon Tyne, United Kingdom

OPEN ACCESS

Edited by:

Changyou Gao,

Zhejiang University, China

Reviewed by:

Yonghui Ding,

Northwestern University

United States

Xiong $\mathrm{Lu}$,

Southwest Jiaotong University, China

*Correspondence:

Ana M. Ferreira

ana.ferreira-duarte@ncl.ac.uk

Piergiorgio Gentile

piergiorgio.gentile@ncl.ac.uk

tThese authors have contributed equally to this work

Specialty section This article was submitted to Biomaterials,

a section of the journa Frontiers in Bioengineering and Biotechnology

Received: 09 April 2020 Accepted: 08 June 2020

Published: 29 June 2020

Citation:

Scalzone A, Bonifacio MA,

Cometa S, Cucinotta F, De Giglio E, Ferreira AM and Gentile P (2020)

$\mathrm{pH}$-Triggered Adhesiveness

and Cohesiveness of Chondroitin Sulfate-Catechol Biopolymer for Biomedical Applications.

Front. Bioeng. Biotechnol. 8:712.

doi: 10.3389/fbioe.2020.00712
Nature provides biomaterials that tend to be effective to control both their adhesive and cohesive properties. A catecholamine motif found in the marine mussels, the mytilus edulis foot protein, can play adhesiveness and cohesiveness. Particularly, acidic $\mathrm{pH}$ drives catechol (Cat) to have adhesive function, resulting in surface coating, while basic $\mathrm{pH}$ allows to enhance its cohesive properties, resulting in the formation of hydrogels. In this work, we demonstrated the usefulness of Cat-conjugated chondroitin sulfate (CS) as a platform for mesenchymal stem cell culture, utilizing the adhesive property of CSCat as coating for different substrates and the cohesive properties as hydrogel for cells encapsulation. To prepare the CS-Cat biopolymer, dopamine (DP) was coupled to the CS by carbodiimide coupling reaction and the Cat content was determined by UV-Vis spectroscopy ( $4.8 \pm 0.6 \%)$. To demonstrate the adhesive properties of the biopolymer, PLA, $\mathrm{PCL}, \mathrm{TiO}_{2}$, and $\mathrm{SiO}_{2}$ substrates were immersed in CS-Cat solution $(\mathrm{pH}<2)$. Following the coating, the surfaces became highly hydrophilic, exhibiting a contact angle less than $35^{\circ}$. Also, in the presence of an oxidizing agent at $\mathrm{pH} 8$, CS-Cat solution immediately became a hydrogel, as shown by inverted-vial test. Finally, immortalized TERT human mesenchymal stem cells (Y201) confirmed the high cytocompatibility of the biopolymer. The CS-Cat coating significantly enabled the Y201 adhesion onto PLA substrates, while the prepared hydrogel demonstrated to be a suitable environment for the encapsulation of cells as suitable bioink for further bioprinting applications.

Keywords: chondroitin sulfate, catechol, soft tissue engineering, human mesenchymal stem cells, hydrogel

\section{INTRODUCTION}

Adhesive and cohesive properties are crucial features for the synthesis of functionalised materials, particularly in the biomedical field for different application, i.e., tissue engineering, cell therapy, microfluidics, etc. Adhesion and cohesion are terms often confused, although their meaning differences are deeply investigated in several books in the medical field. Adhesive means any attraction between different molecular species, brought into direct contact as the adhesive could stick or binds to the applied surface; while cohesive means attraction that occurs between similar 
molecular species, as results of chemical bonds between the single components of the adhesive agents (Von Fraunhofer, 2012).

Recently, biomimetic strategies based on the surface immobilization of biopolymers have been used to enhance the adhesive property to control the cellular behavior with biointerfaces created by binding biologically inert and/or active molecules on solid substrates (Neto et al., 2014; Brennan et al., 2016), improve the stability and release of biomolecules by their surface immobilization chemically or physically (Kim et al., 2015; Xu et al., 2015), or actively modify. Instead, cohesive properties have been crucial for the manufacturing of 3D scaffolds, such as hydrogels for soft tissue regeneration.

Nature provides biomaterials that tend to have an effective approach to control both their adhesive and cohesive properties. Considering the before mentioned requirements, various hydrogels-based bioadhesive systems have been exploited, with several inspired by marine mussels because of the adhesive strength of mussel foot proteins within a wet environment and the adaptable chemistry of catechol (Cat) groups. In particular, there is a Cat amine motif found in the marine mussels, the mytilus edulis foot protein (3,4-dihydroxy-L-phenylalanine and lysine), able to play adhesiveness and cohesiveness, based on the pH (Waite and Tanzer, 1981; Lee et al., 2007). Particularly, acidic $\mathrm{pH}$ drives Cat to have an adhesive function, obtaining a surface coating, while basic $\mathrm{pH}$ allows to increase its cohesive properties, resulting in the formation of hydrogels (Ryu et al., 2015). As far as the adhesiveness is concerned, Cat moieties establish strong interactions with several different mechanisms, i.e., covalent bonds, hydrogen bonds, $\pi-\pi$ stacks, and coordination bonds (Saiz-Poseu et al., 2019; Xie et al., 2020). Conversely, in an alkaline environment, the formation of transient quinone groups leads to crosslinking reactions (e.g., dismutation and Cat-Cat bonds, hydrogen bonds, and van der Waals and other cohesive forces established with the polymeric chains), as previously reported (Yang J. et al., 2014).

The Cat moiety has been chemically included into a variety of polymers, including poly(ethylene glycols) (PEG-Cat) (Lee et al., 2010), alginate (Alg-Cat) (Lee et al., 2013), heparin (HepCat) (Yang Y. et al., 2014), poly(vinyl alcohol) (PVA-Cat) (Son et al., 2013), poly(acrylic acid) (PAA-Cat) (Krogsgaard et al., 2013), dextran (Dex-Cat) (Park J. Y. et al., 2013), $\operatorname{poly}(N$ isopropyl acrylamide) (PNIPAM-Cat) (Marcelo et al., 2014), poly(styrene) (PS-Cat) (Matos-Pérez et al., 2012), and finally chitosan (Chi-Cat) (Ryu et al., 2011; Kim et al., 2013; Han et al., 2018). Furthermore, biopolymers chemically conjugated to Cat can exhibit both adhesive and cohesive properties, based on the conditions of the surrounding environment. Hong et al. (2013) synthesized successfully hyaluronic acid (HA)Cat conjugates and demonstrated their usefulness in neural stem cell engineering, showing an improved cells viability of the conjugated films and hydrogels compared with the systems based on HA only. Interestingly, the human neural stem cells underwent a spontaneous differentiation without mitogenic factors independently of the molecular weight of the conjugated HA biopolymers (ranging from 50 to $700 \mathrm{kDa}$ ). In a similar work, HA-Cat adhesive coating enhanced endothelial cell adhesion in a microfluidic-based shear assay, characterized by both hydrophilic and hydrophobic surfaces (Joo et al., 2016). Recently, properties of HA-Cat as tissue-adhesive hydrogel for enhancing biocompatibility and mediating minimally invasive cell therapy were investigated, obtaining improved therapeutic potency in pathological or defected animal models (Shin et al., 2015).

In this work, a novel chondroitin sulfate (CS)-Cat biomaterial has been engineered with bio-adhesiveness and cohesiveness, at different conditions, for regenerative medicine applications. Among the other natural polymers, CS is a less expensive proteinous natural polymer, composed of sulfated glycosaminoglycan (GAG) that is found in connective tissues, synovial fluid, hyaline cartilage, and bones, where it aids resistance toward compression. It has been described to be effective in pain relief and improvement of soft tissue regeneration, such as neural, musculoskeletal, skin (Lingor et al., 2007; Varghese et al., 2008; Salbach et al., 2012; Montell et al., 2017; Farrugia et al., 2018). Furthermore, due to its high versatility, CS has also been studied in wound healing, promoting effect and tissue regeneration after surgical operations. Recently, dopamine (DP), having a structure similar to marine musselsecreted adhesion proteins, was found to possess strong adhesion to numerous substrates enhancing cells attachment and proliferation. The introduction of Cat groups helped to greatly enhance the adhesive ability and cytocompatibility of CS. The developed CS-Cat formulation can represent a promising candidate as bioadhesive formulation for future biomedical applications, possessing strong adhesive properties at acid $\mathrm{pH}$, supporting mesenchymal stem cells viability, proliferation, and metabolic activity, via reactions with cells membrane reactive groups (amino, carboxyl, and Cat). These properties were examined through viability and cells morphology analysis. While the CS-Cat formulation at basic $\mathrm{pH}$ showed an excellent cytocompatibility, hosting TERT-human mesenchymal stem cells encapsulated within the hydrogel as confirmed by our in vitro viability tests. These results, together with the mechanical and water uptake (WU) analysis, demonstrated the potential of this hydrogel to encapsulate high cell density to be used as bioink for bioprining constructs for tissue engineering applications.

\section{MATERIALS AND METHODS}

\section{Materials}

Chondroitin 4-sulfate sodium salt from bovine trachea (CS; $\mathrm{MW}=515.376 \mathrm{~g} / \mathrm{mol})$, DP hydrochloride $(\mathrm{MW}=189.64 \mathrm{~g} / \mathrm{mol})$, sodium periodate $\left(\mathrm{NaIO}_{4} ; \mathrm{MW}=231.89 \mathrm{~g} / \mathrm{mol}\right), 2-(\mathrm{N}-$ Morpholino)ethane sulfonic acid (MES; MW = $195.24 \mathrm{~g} / \mathrm{mol}$ ), sodium chloride $(\mathrm{NaCl} ; \quad \mathrm{MW}=58.44 \mathrm{~g} / \mathrm{mol}) 1$-ethyl-3(3-dimethylaminopropyl)-carbodiimide hydrochloride (EDC; $\mathrm{MW}=191.70 \mathrm{~g} / \mathrm{mol})$, dialysis tubing cellulose membrane $($ MWCO $=14,000 \mathrm{~g} / \mathrm{mol}$ ), sodium hydroxide $(\mathrm{NAOH} ; \quad \mathrm{MW}=40 \mathrm{~g} / \mathrm{mol})$, N-hydroxy succinimide (NHS; $M W=115.09 \mathrm{~g} / \mathrm{mol}$ ), Dulbecco's Modified Eagle Medium (DMEM), phosphate buffer saline (PBS), and ethyl alcohol solution (ETOH) were supplied by Sigma-Aldrich (United Kingdom). All the experiments were performed with the ultrapure water obtained with a Milli-Q ${ }^{\circledR}$ (United Kingdom) 
Integral system, equipped with a BioPak ${ }^{\circledR}$ ultrafiltration cartridge (Millipore, Merck, United States).

\section{Methods for the CS-Cat Samples Preparation \\ Synthesis of Conjugated CS-Cat}

Chondroitin sulfate $(5 \mathrm{~g})$ was dissolved in $50 \mathrm{~mL}$ of an activation buffer at $\mathrm{pH}$ 6.0, consisting in MES $0.1 \mathrm{M}$ and $\mathrm{NaCl} 0.5 \mathrm{M}$. EDC (1.82 g) and NHS (1.1 g) were slowly added to the buffer, until a final molar ratio of 1:1:1 CS/EDC/NHS was reached. DP $(1.8 \mathrm{~g})$ was added after $30 \mathrm{~min}$ of stirring, maintaining the $\mathrm{pH}$ constant (5.5-6) for $4 \mathrm{~h}$. Subsequently, the unreacted molecules were removed by dialysis, performed for 1 day in $0.1 \mathrm{M} \mathrm{MES}$ aqueous solution, then for 2 days in acidified distilled water $(\mathrm{pH}<2)$. Finally, the purified product was freeze-dried, resulting in a whitish powder. During all the synthesis steps, the solution was protected from the visible light by covering the beaker with aluminum foil. UV-visible spectroscopy (UV-1800 UV-Vis Spectrophotometer, Shimadzu) was exploited to check the Cat content in CS-Cat through its absorbance at $280 \mathrm{~nm}$. In this respect, a calibration curve was built with DP standard solutions.

\section{Surface Coating on Different Substrates}

Chondroitin sulfate-Cat was dissolved in $1 \mathrm{x}$ PBS solution at a $2 \%$ (w/v) concentration; $\mathrm{NaIO}_{4}$ was used as an oxidizing agent, at a molar ratio of $1.5: 1$ with Cat. Then, the $\mathrm{pH}$ was reduced to 2 and $100 \mu \mathrm{L}$ of polymer solution were deposited onto the center of the selected substrates, then spin-coated (Bench Top Spin Coater, MTI tech, Ltd.) at $1000 \mathrm{r} / \mathrm{min}$ for $3 \mathrm{~s}$ followed by $10 \mathrm{~s}$ at $7000 \mathrm{r} / \mathrm{min}$ for obtaining a homogenous thin film. This procedure was repeated twice. The selected substrates were based on glass (microscope coverslip), polycaprolactone (PCL), polylactic acid (PLA), and $\mathrm{TiO}_{2}$.

\section{Formation of CS-Cat Hydrogels}

Chondroitin sulfate-Cat hydrogels were formed by the crosslinking of Cat groups. Two different concentrations were exploited [10 and 20\% (w/v)]. First, CS-Cat was dissolved in $\mathrm{PBS}$ at both concentrations. The $\mathrm{pH}$ of the solution was adjusted to 8-9 by adding $1 \mathrm{M} \mathrm{NaOH}$. When $\mathrm{NaIO}_{4}$ was added, the sol/gel transition and the obtainment of a CS-Cat hydrogel happened spontaneously without any further treatment. The gelation time of the hydrogel was measured while varying the amount of $\mathrm{NaIO}_{4}$ (from 1.0 to 2.0 equivalents to the molar amount of Cat). The gelation time was determined when the solution flow stopped inverting the vial.

\section{Characterization Tests Chemical Characterization by NMR, XPS, and ATR-FTIR}

${ }^{1} \mathrm{H}$ and ${ }^{13} \mathrm{C}$ nuclear magnetic resonance (NMR) spectroscopy spectra were recorded with either Bruker AVANCE $300 \mathrm{MHz}$ or JEOL $400 \mathrm{MHz}$ spectrometers operating at $25^{\circ} \mathrm{C}$. Samples were prepared in $5 \mathrm{~mm}$ NMR tubes by dissolving the compounds in appropriate deuterated solvents. Chemical shifts are reported in ppm relatively to TMS as internal standard.
$\mathrm{X}$-ray photoelectron spectroscopy (XPS) was carried out to study the elemental composition of the CS-Cat conjugate. A PHI 5000 VersaProbe II (Physical Electronics, United States) was exploited, with an AlK $\alpha$ X-ray radiation source. The freeze-dried samples were examined recording survey scans $(0-1200 \mathrm{eV})$ and high-resolution signals in Fixed Analyzer Transmission mode (pass energy $29.35 \mathrm{eV}$ ), scanning areas of $\sim 1400 \times 200 \mu \mathrm{m}$. The MultiPak software (v. 9.9.0) was exploited for data mining. The surface elemental composition was assessed after normalizing each peak area, referring to the software library for elemental sensitivity factors. High-resolution spectra were fitted with Gaussian-Lorentzian peaks having the same FWHM.

Attenuated total reflection-Fourier transform infra-red (ATRFTIR) analysis was performed on a Spectrum Two PE instrument using the Universal ATR accessory (Single Reflection Diamond) (PerkinElmer Inc., Waltham, MA, United States) in a range of $4000-550 \mathrm{~cm}^{-1}$ (resolution $4 \mathrm{~cm}^{-1}$ ). Dried samples were analyzed without any preliminary preparative step.

\section{Contact Angle Measurements}

Static contact angle analyses were performed with a CAM 200 KSV instrument (KSV Instruments, Finland), using the software Drop Shape Analysis System DSA 10 (V2.0-02, KRUSS GmbH, Germany). Distilled water drops $(3 \mu \mathrm{L})$ were used for each analysis, repeated at least three times per sample. Results were expressed as mean \pm standard deviation.

\section{Morphological Analysis by Scanning Electron Microscopy}

Hydrogels morphological analysis was performed on freezedried samples [lyophilization took place for $48 \mathrm{~h}$ (Christ ALPHA 1-2/LD Plus, Martin Christ, Germany)] by scanning electron microscopy (SEM, HITACHI TM3030, Maidenhead, United Kingdom). The diameters of the pores were evaluated on five SEM micrographs using ImageJ software.

\section{Water Uptake}

The WU test was performed on the freeze-dried samples. Each sample was weighted and placed separately in a $5 \mathrm{~mL}$ vial with the addition of $3 \mathrm{~mL}$ of PBS and stored at $37^{\circ} \mathrm{C}$. The weight of all the samples was measured before the immersion $\left(\mathrm{W}_{\mathrm{i}}\right)$ and at different time points $\left(\mathrm{W}_{\mathrm{t}}\right): 30 \mathrm{~min}, 1,2,4,6,24$, and $48 \mathrm{~h}$ of incubation. At each time point, the samples were weighted, after gently drying the extra PBS on the surface using tissue papers. The WU percentage was calculated using the following equation at each time point:

$$
W U(\%)=\frac{W_{t}-W_{i}}{W_{i}} \times 100
$$

\section{Mechanical Properties by Unconfined Compression Test}

Unconfined compression tests were performed in triplicate on $10 \% \mathrm{w} / \mathrm{v}$ and $20 \% \mathrm{w} / \mathrm{v}$ CS-Cat samples using a universal testing machine (EZ-SX, Shimadzu, Japan) provided of a $20 \mathrm{~N}$ load cell and crosshead speed set at $1 \mathrm{~mm} \cdot \mathrm{min}^{-1}$. The measurement was stopped once the strain reached the $35 \%$. Then, the stress/strain 
$(\sigma / \varepsilon)$ curves, for both sample types, were plotted and the respective compressive Young's moduli (E) were calculated as the slope of the initial elastic region of the curves (0-10\% strain).

\section{In vitro Biological Tests \\ Cell Culture}

The immortalized cell line Y201 derived from human mesenchymal stem cells (Y201) were kindly provided by Prof. P. Genever (York University) and cultured as already described (James et al., 2015). Cells were grown at $37^{\circ} \mathrm{C}, 5 \%$ $\mathrm{CO}_{2}$, in DMEM with low glucose content, with the addition of $10 \%$ fetal bovine serum (FBS), $2 \mathrm{mM} \mathrm{L}$-glutamine, and a $1 \%$ penicillin-streptomycin $(\mathrm{P} / \mathrm{S})$ mixture $(100 \mathrm{U} / \mathrm{mL})$.

\section{Cell Viability and Morphological Analysis Assessment on the Coated Substrates}

The biological behavior of Y201 cells was examined on PLACS-Cat spin-coated substrate and compared with uncoated PLA substrate and tissue culture plate (TCP). Prior to cells seeding, all samples were sterilized with $70 \% \mathrm{ETOH}$ for $20 \mathrm{~min}$ and treated with Sudan Black (SB) to limit auto fluorescence. Each sample was covered with $50 \mu \mathrm{L}$ of SB solution $[0.3 \%(\mathrm{w} / \mathrm{v})$ in EthOH], incubated for $20 \mathrm{~min}$ at $37^{\circ} \mathrm{C}$ and washed properly twice with PBS. Then samples were sterilized under a UV lamp for $30 \mathrm{~min}$ and placed in 48 -well plate. The cell density was $5 \times 10^{4}$ cells per sample. Cells viability was studied via Live/Dead staining (Live/Dead Cell Staining Kit II, PromoKine, PromoCell GmbH, Germany) after 1 and 3 days of culture for each sample, following the manufacturer's protocols. In this kit, calcein AM and ethidium bromide are combined to provide two-color discrimination based on the cells state: live cells in green and dead cells in red. All the samples were washed with PBS and the staining solution, prepared diluting $4 \mu \mathrm{M}$ ethidium homodimer-1 and $10 \mu \mathrm{M}$ calcein in PBS, was added to the samples. Following this, samples were incubated for $30 \mathrm{~min}$ at $37^{\circ} \mathrm{C}$ and images were collected at each time point using a fluorescence microscope (EVOS M5000).

To assess the cells metabolic activity, the culture medium was removed at each time point (1 and 3 days), samples were washed with PBS and $1 \mathrm{~mL}$ of PrestoBlue stock solution, obtained from a dilution (1:10) of PrestoBlue ${ }^{\mathrm{TM}}$ reagent (Thermo Scientific, United Kingdom) in DMEM, was added to each well and incubated for $2.5 \mathrm{~h}$ at $37^{\circ} \mathrm{C}$ and $5 \% \mathrm{CO}_{2}$. Then, $200 \mu \mathrm{L}$ of each well solution (in triplicate) was transferred to a 96-well plate and a spectrophotometer (FLUOstar OMEGA microplate reader) was used to measure the fluorescence (excitation/emission of $560 / 590 \mathrm{~nm}$ ). Following, samples were washed with PBS and fresh DMEM was added for the next time point. All this experiment was performed in light-covered conditions (Scalzone et al., 2019). To evaluate the cells morphology and their adhesion to the substrates, immunostaining analysis were performed. Samples were fixed in pre-warmed $4 \% \mathrm{w} / \mathrm{v}$ paraformaldehyde (PFA) and cells were permeabilized with $0.1 \%(\mathrm{v} / \mathrm{v})$ Tween $20^{\circledR}$ in PBS. Rhodamine-phalloidin solution was prepared using phalloidin-tetramethylrhodamine $B$ isothiocyanate (1:1000 in $0.1 \% \mathrm{PBS} / \mathrm{Tween}^{\circledR} 0^{\circledR}$ ) for $30 \mathrm{~min}$ at room temperature. Then, samples were washed with $0.1 \%$ PBS/Tween $20^{\circledR}$ and
DAPI solution (Vector Laboratories, United Kingdom) was added $\left(1: 2500\right.$ in $\left.0.1 \% \mathrm{PBS} / \mathrm{Twween} 0^{\circledR}\right)$ for $15 \mathrm{~min}$ at room temperature. Images were collected at 7 days using a fluorescence microscope (EVOS M5000).

\section{Cell Encapsulation Within the CS-Cat Hydrogel}

The biological behavior of Y201s was even examined within CS-Cat hydrogels. Prior to cells encapsulation, CS-Cat freezedried powder was sterilized under a UV lamp for $30 \mathrm{~min}$. For the cell encapsulation CS-Cat $20 \%(w / v)$ solution $(100 \mu \mathrm{L})$ was poured into a 24-well plate membrane-based cell culture insert (membrane pore size of $8.0 \mu \mathrm{m}$, Merck, Millipore, Germany) at room temperature. The same procedure explained before for the hydrogel preparation was followed and Y201s were added before the $\mathrm{NaIO}_{4}$ addition and mixed gently with the hydrogel solution at an optimized cellular density of $2 \times 10^{6}$ cells $/ \mathrm{mL}$ (Liu et al., 2017). Finally, $1 \mathrm{~mL}$ of fresh DMEM was added to each well and changed three times per week. Samples were stored in the incubator at $37^{\circ} \mathrm{C}, 5 \% \mathrm{CO}_{2}$.

\section{Biological Assessments: Metabolic Activity and Viability of Encapsulated Cells}

The Live/Dead staining was exploited to study cell viability at day 1 and day 3. The experiment was performed as explained before for the coated substrate and samples were imaged with Nikon A1R inverted confocal microscope. To assess cells metabolic activity, the culture medium was removed at each time point ( 1 , 3 , and 7 days) and samples were washed with PBS. Then, $1 \mathrm{~mL}$ of Alamar Blue solution obtained from a dilution (1:10) of Alamar Blue $^{\mathrm{TM}}$ reagent (Thermo Scientific, United Kingdom) in DMEM protected from light, was added to each well with the gel and incubated for $2.5 \mathrm{~h}$ at $37^{\circ} \mathrm{C}$ and $5 \% \mathrm{CO}_{2}$. Then, $200 \mu \mathrm{L}$ of each well solution (in triplicate) was transferred to a clear bottom 96well plate and a filter-based multi-mode microplate reader was used to measure the absorbance at $630 \mathrm{~nm}$. Following, samples were washed with PBS twice and fresh media was added for the next time point. For the immunostaining analysis, samples were fixed as explained previously and DAPI staining was performed. Images were collected at 3 and 7 days using a Nikon A1R inverted confocal microscope.

\section{Statistical Analysis}

The statistical significance of the obtained results was assessed using GraphPad Prism Software (v. 8.4.1). One-way ANOVA with repeated measurements was performed for each experiment. Then, Tukey's post hoc test was carried out to highlight the main factors determining data variability. Statistical significance was set at $* p<0.05$ and ${ }^{* * * *} p<0.0001$.

\section{RESULTS}

\section{CS-Cat Synthesis}

To prepare the CS-Cat conjugate, EDC coupling reaction was used to bind DP with the carboxyl group of CS as shown in Figure 1. The reaction occurred for $4 \mathrm{~h}$ in an aqueous activation buffer at constant $\mathrm{pH}(5.5-6)$. 

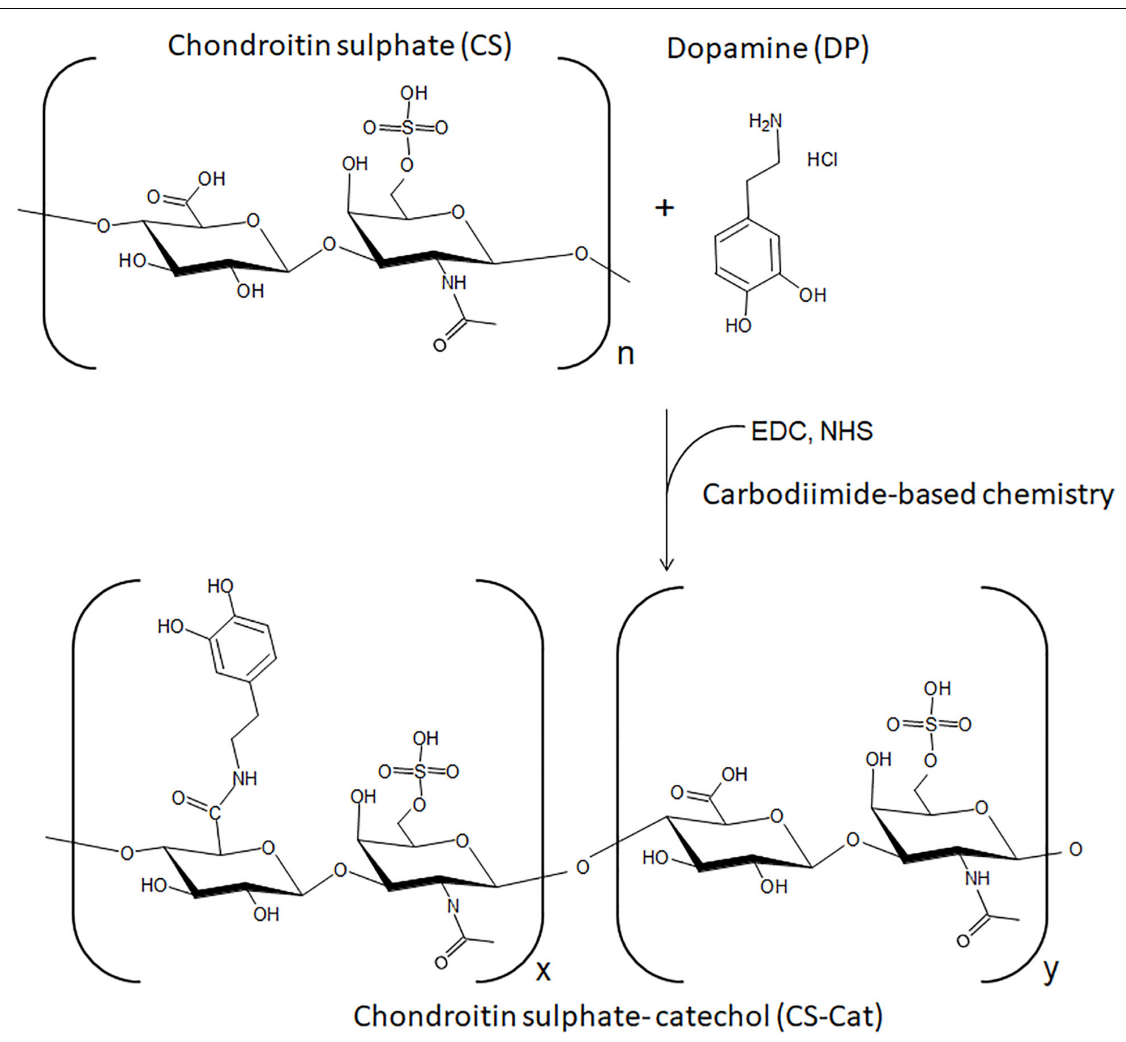

FIGURE 1 | Schematic representation of CS-Cat conjugates and reaction process.

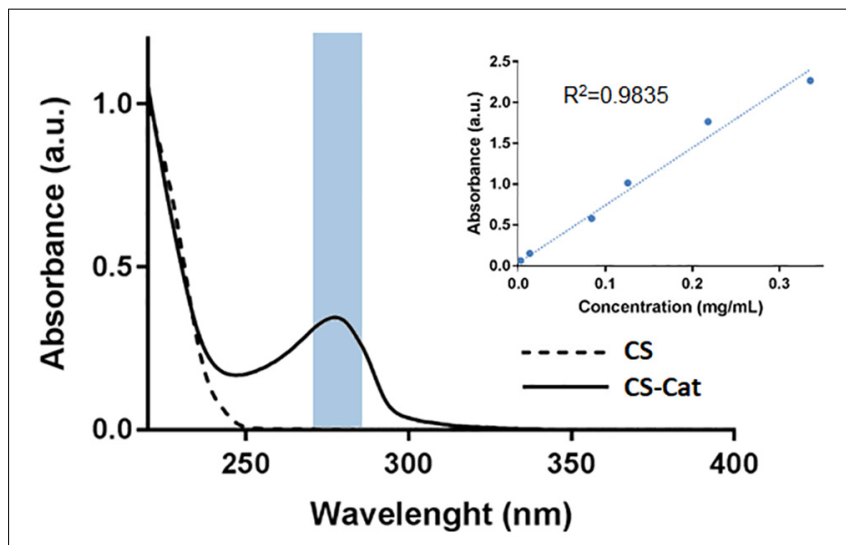

FIGURE 2 | Catechol quantification by UV-Vis analysis, with a peak at $280 \mathrm{~nm}$. The lack of peak after $300 \mathrm{~nm}$ demonstrated that the CS-Cat was not oxidized.

The results obtained by UV-Vis spectroscopy are reported in Figure 2. It can be observed at $280 \mathrm{~nm}$ a single absorbance peak, relative to the DP (Chen and Peng, 2003), that was not evident in the pure CS sample. The Cat content was determined at $280 \mathrm{~nm}$ and, comparing with the DP standard calibration curve, it resulted that approximately $4.8 \pm 0.6 \%(n=3)$ of the carboxylic acid groups in the CS chain were conjugated with DP. Moreover, no additional peaks at wavelengths higher than $300 \mathrm{~nm}$ were observed, showing that the conjugated Cat was not oxidized.

Different methods were performed to determine the Cat grafting and content. Indeed, the product of the synthesis of the conjugate reaction was analyzed by NMR spectroscopy and XPS. Comparing the two obtained NMR spectra (Figure 3), the CS sample presents some peaks between 1.9 and $2.3 \mathrm{ppm}$ : (i) representative of the $N$-acetyl methyl group typical of CS, two peaks at 3.6 and $4.43 \mathrm{ppm}$, (ii) representative of the Dglucuronic acid and at 4.6 and $4.75 \mathrm{ppm}$, and (iii) representative of the $N$-acetyl-D-galactosamine, which are specifics of the chondroitin-4-sulfate (Toida et al., 1993; Üstün et al., 2011). All these peaks were re-found in the CS-Cat spectra, with the additions of new peaks: the multi-peaks centered at $\mathrm{d} 2.75 \mathrm{ppm}$ (i) and $3.2 \mathrm{ppm}$ (ii) in the CS-Cat spectrum represent the two methylene groups brought by DP after they were grafted onto the CS backbones (Imperiale et al., 2013). The multi-peaks centered at $6.75 \mathrm{ppm}$ (iii) and $6.89 \mathrm{ppm}$ (iv) represent the corresponding methine groups located on the benzene ring of grafted DP. After the chemical reaction between CS and DP, there was still a small amount of NHS residue in the resultant CS-Cat polymers (peaks centered at d 0.8-0.9 ppm; $v$ ).

$\mathrm{X}$-ray photoelectron spectroscopy data, reported in Table 1, compared the surface elemental compositions of pure DP, CS, and CS-Cat adduct.

The resulting elemental composition analysis of DP indicates that the experimentally measured $\mathrm{C} / \mathrm{O}$ and $\mathrm{C} / \mathrm{N}$ ratios were 

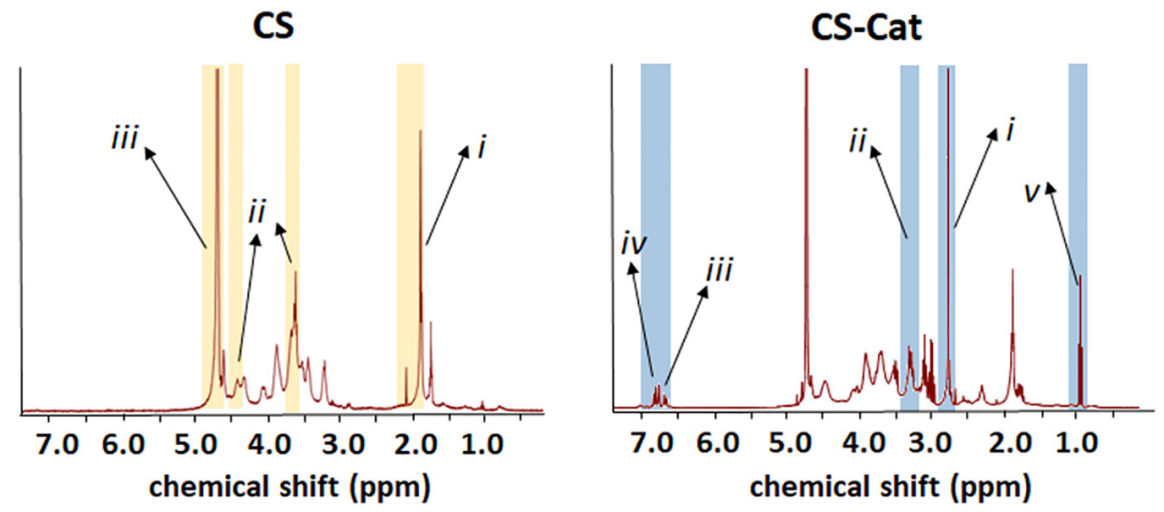

FIGURE 3 | Chemical properties of synthesized CS-Cat materials: NMR spectra of CS-Cat (on the right) and the CS as control (on the left).

TABLE 1 | surface elemental composition of DP, CS, and CS-Cat.

\begin{tabular}{lllllll}
\hline Sample & \multicolumn{7}{c}{ Atomic \% } \\
\cline { 2 - 7 } & C1s & O1s & N1s & C12p & Na1s & S2p \\
\hline DP & 68.8 & 16.0 & 8.1 & 7.1 & - & - \\
CS & 51.0 & 36.1 & 5.8 & 0.6 & 4.3 & 2.2 \\
CS-Cat & 56.7 & 30.3 & 7.8 & 0.9 & 2.6 & 1.7 \\
\hline
\end{tabular}

4.3:1 and 9.7:1, respectively. These values are consistent with the stoichiometric ratios expected for the Cat molecule (i.e., $4: 1$ and $8: 1$, respectively), taking into account the adventitious hydrocarbon contamination onto all the surfaces. The XPS compositions of CS and CS-Cat surfaces resulted quite similar in terms of detected elements.

Typical high-resolution XPS C1s spectra for DP, CS, and CSCat are shown in Figure 4. The carbon peaks detected in the $\mathrm{C} 1 \mathrm{~s}$ spectra and the relevant percentages are summarized in Figures 4A-C. In DP C1s signal (Figure 4A), three contributions were detected: the first one, at $284.8 \mathrm{eV}$, typical of hydrocarbons present in the aromatic ring; a second very low peak, at $285.4 \mathrm{eV}$, relevant to $\mathrm{C}-\mathrm{N}$ contribution; the third one, at $286.3 \mathrm{eV}$, ascribable both to $\mathrm{C}-\mathrm{OH}$ and $\mathrm{C}-\mathrm{NH}_{3}+$ groups. Indeed, DP was present mainly in the hydrochloride form, as confirmed also by the almost similar chlorine and nitrogen atomic percentages (Table 1).

As far as the CS C1s curve fitting (Figure 4B), a typical polysaccharide carbon shape was observed, deconvoluted by five components. The first one at $284.8 \mathrm{eV}$, due to hydrocarbon contamination; the second at $285.4 \mathrm{eV}$, ascribable to carbon in $\alpha$-position to carboxylic moieties; the third, typical of $\mathrm{C}-\mathrm{OH}$ and $\mathrm{C}-\mathrm{O}-\mathrm{C}$ bonds present in carbohydrates; the forth at $287.9 \mathrm{eV}$, containing the anomeric carbon $(\mathrm{O}-\mathrm{C}-\mathrm{O})$, the $\mathrm{C}-$ $\mathrm{O}-\mathrm{SO}_{3}{ }^{-}$, and the carbon in the amide $(\mathrm{C}=\mathrm{O}-\mathrm{NH})$ present in CS; finally, the fifth contribution, relevant to carboxylic carbon $(\mathrm{C}=\mathrm{O}-\mathrm{OR})$.

When the CS-Cat adduct was formed, the C1s curve fitting (Figure 4C) presented similar contributions to CS sample, except for the relative atomic percentages of each contribution. Curve fitting of high-resolution N1s spectra was performed as well. Figures 4D-F show N1s curve fitting of DP, CS, and CS-Cat spectra. The relevant binding energies and atomic percentages are reported in the table. N1s spectrum of DP (Figure 4D) exhibited almost protonated amine groups, evidenced by the peak at $401.7 \mathrm{eV}$, with a low presence (about 6\%) of neutral amine groups, in good agreement with C1s curve fitting. CS specimen (Figure 4E) presented only amide contribution, falling at $400.0 \mathrm{eV}$, as expected. Finally, CS-Cat (Figure 4F) presented two contribution: the first one, at $400.0 \mathrm{eV}$, due to amide groups already present in CS in addition to those created from the DP grafting; the second, falling at $401.8 \mathrm{eV}$, ascribable both to unloaded DP and to residue ester linkage between NHS and CS.

\section{CS-Cat as Tissue Adhesive Coating Physico-Chemical Characterization}

To demonstrate the ability of the CS-Cat to coat any surface, substrates in PLA, PCL, $\mathrm{TiO}_{2}$, and $\mathrm{SiO}_{2}$ were covered by spincoating with a CS-Cat solution at $\mathrm{pH}<2$, as reported before in Section "Surface Coating on Different Substrates," and then washed with distilled water. The CS-Cat coating thickness was ranging from 25 to $40 \mu \mathrm{m}$ measured by SEM analysis. The surface was characterized by infrared spectroscopy (FTIR-ATR). Figure 5A shows the spectrum of the CS-Cat coating on the PCL sample. Methylene groups $\left(-\mathrm{CH}_{2}\right)$ were observed at $2940-2920$ and 2860-2850 $\mathrm{cm}^{-1}$, while the amide $\mathrm{C}=\mathrm{O}$ stretching signals fell at $1700-1250 \mathrm{~cm}^{-1}$. Carboxylate moieties $\left(\mathrm{COO}^{-}\right)$belonging to salts were detected at $1650-1500 \mathrm{~cm}^{-1}$, while the $\mathrm{NH}$ bending signal was recorded at $1560-1530 \mathrm{~cm}^{-1}$. The primary $-\mathrm{OH}-$ stretch occurred at $3640-3630 \mathrm{~cm}^{-1}$, beyond the signal at $3350-$ $3250 \mathrm{~cm}^{-1}$. Ethers' contribution (-C-O-C-) was observed at $1100 \mathrm{~cm}^{-1}$.

In addition, contact angle analyses were exploited to characterize surface physico-chemical changes due to CS-Cat. The latter induced a hydrophilic feature, with a considerable decrease in the contact angle of the coated substrates compared to the bare ones: $\mathrm{SiO}_{2}$ (from $64.2^{\circ} \pm 3.4^{\circ}$ to $13.5^{\circ} \pm 2.7^{\circ}$ ), PCL (from $66.1^{\circ} \pm 3.8^{\circ}$ to $28.2^{\circ} \pm 3.8^{\circ}$ ), PLA (from $78.2^{\circ} \pm 2.6^{\circ}$ 

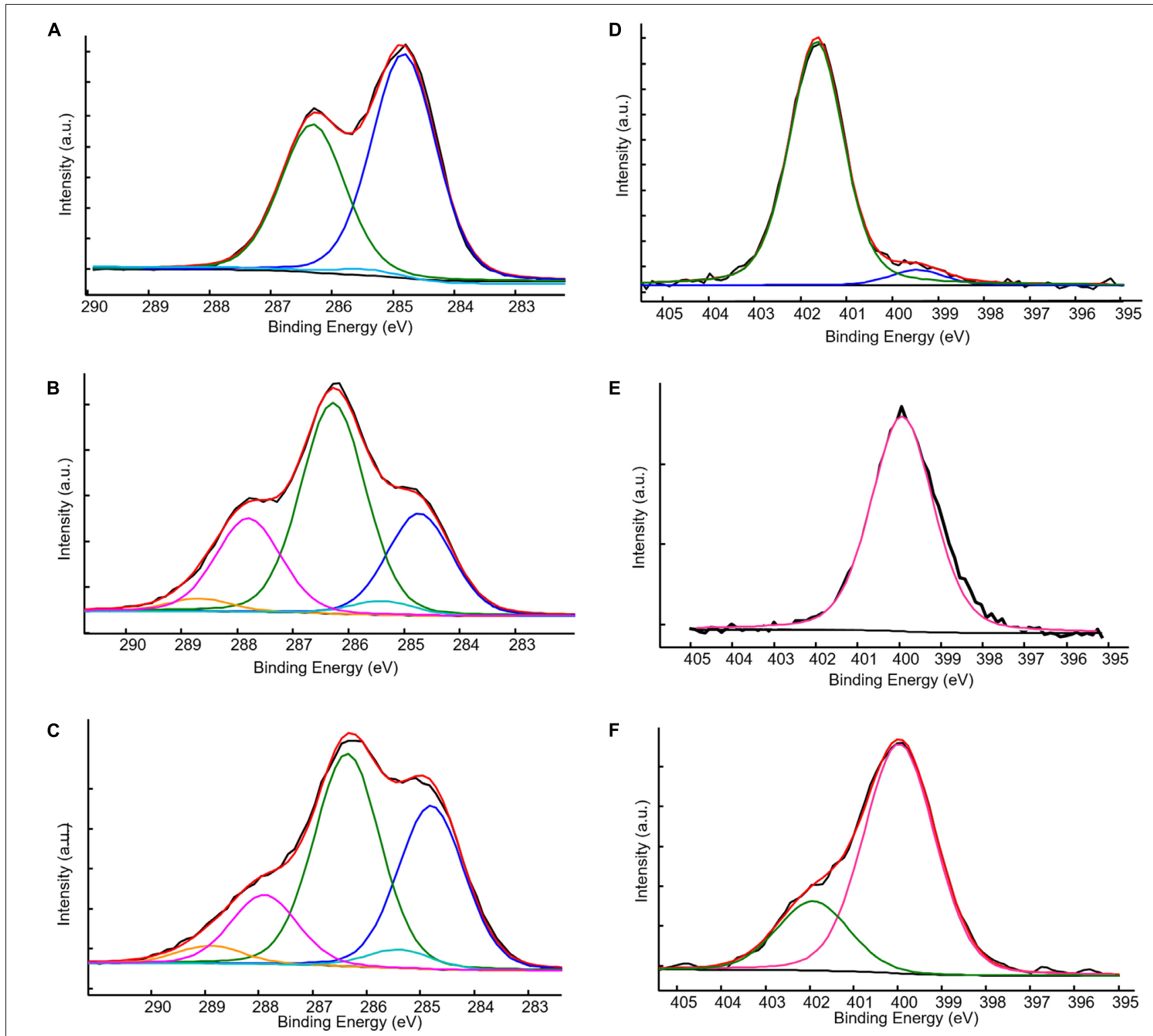

\begin{tabular}{|c|c|c|c|c|c|c|c|c|}
\hline \multirow[b]{2}{*}{ Sample } & \multicolumn{8}{|c|}{$\begin{array}{c}\mathrm{BE}(\mathrm{eV}) / \\
\mathrm{At} \%\end{array}$} \\
\hline & $\mathbf{C H}_{\mathbf{x}}$ & $\begin{array}{l}\text { C-COOR, } \\
\text { C-NH }\end{array}$ & $\begin{array}{l}\mathrm{C}-\mathrm{OH}, \\
\mathrm{CH}_{-} \mathrm{NH}_{3}{ }^{+}\end{array}$ & $\begin{array}{l}\mathrm{O}-\mathrm{C}-\mathrm{O}, \\
\mathrm{C}-\mathrm{O}-\mathrm{SO}_{3}{ }^{-}, \\
\mathrm{CO}-\mathrm{NH}\end{array}$ & COOR & $\mathrm{NH}_{2}$ & NH-C $=\mathrm{O}$ & $\mathrm{NH}_{3}^{+}$ \\
\hline DP & $\begin{array}{l}284.8 / \\
59.3 \% \\
\end{array}$ & $\begin{array}{c}285.4 / \\
0.9 \% \\
\end{array}$ & $\begin{array}{l}286.3 / \\
39.8 \% \\
\end{array}$ & -- & -- & $\begin{array}{l}399.5 / \\
5.8 \%\end{array}$ & -- & $\begin{array}{l}401.7 / \\
94.2 \%\end{array}$ \\
\hline CS & $\begin{array}{l}284.8 / \\
23.6 \%\end{array}$ & $\begin{array}{l}285.4 / \\
3.5 \%\end{array}$ & $\begin{array}{l}286.3 / \\
49.6 \%\end{array}$ & $\begin{array}{l}287.9 / \\
20.4 \%\end{array}$ & $\begin{array}{l}288.8 / \\
3.0 \%\end{array}$ & -- & $\begin{array}{l}400.0 \\
100 \%\end{array}$ & -- \\
\hline CS-Cat & $\begin{array}{l}284.8 / \\
34.0 \%\end{array}$ & $\begin{array}{l}285.4 / \\
3.9 \%\end{array}$ & $\begin{array}{l}286.4 / \\
44.1 \%\end{array}$ & $\begin{array}{l}287.9 / \\
14.4 \%\end{array}$ & $\begin{array}{l}288.9 / \\
3.6 \%\end{array}$ & -- & $\begin{array}{l}400.0 / \\
77.3 \%\end{array}$ & $\begin{array}{l}401.8 / \\
22.7 \%\end{array}$ \\
\hline
\end{tabular}

FIGURE 4 | C1s (A-C) and N1s (D-F) high-resolution spectra and relevant curve fittings of DP (A,D), CS (B,E), and CS-Cat (C,F) specimens. Attributions, binding energies, and atomic percentages are reported in the table. 

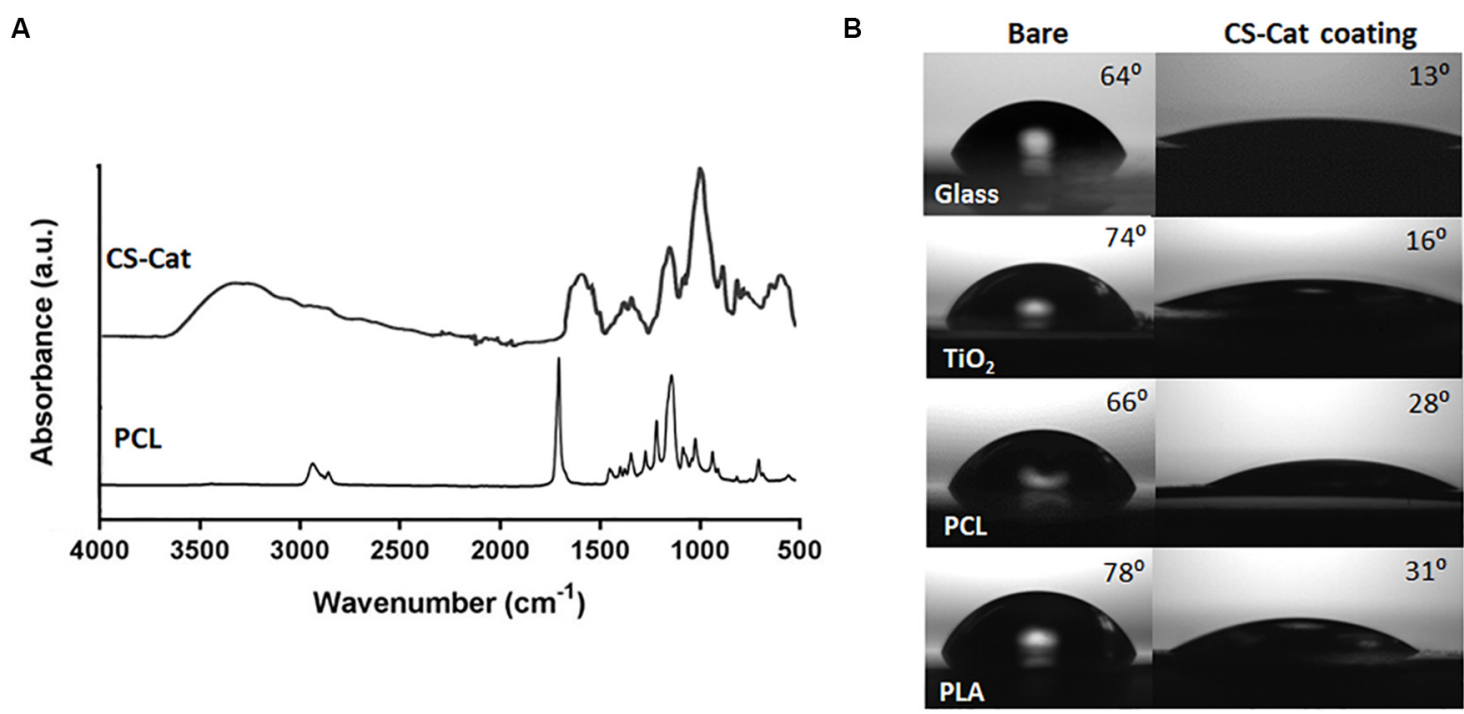

FIGURE 5 | Physico-chemical modification of different substrates, i.e., glass, synthetic polymers (PCL and PLA), and metal oxides (TiO 2 ) with CS-Cat coating. (A) FTIR-ATR spectrum of the bare PCL surface and after coating with CS-Cat. (B) Static contact angle analyses of the four substrates (on the left) and after CS-Cat coating (on the right).
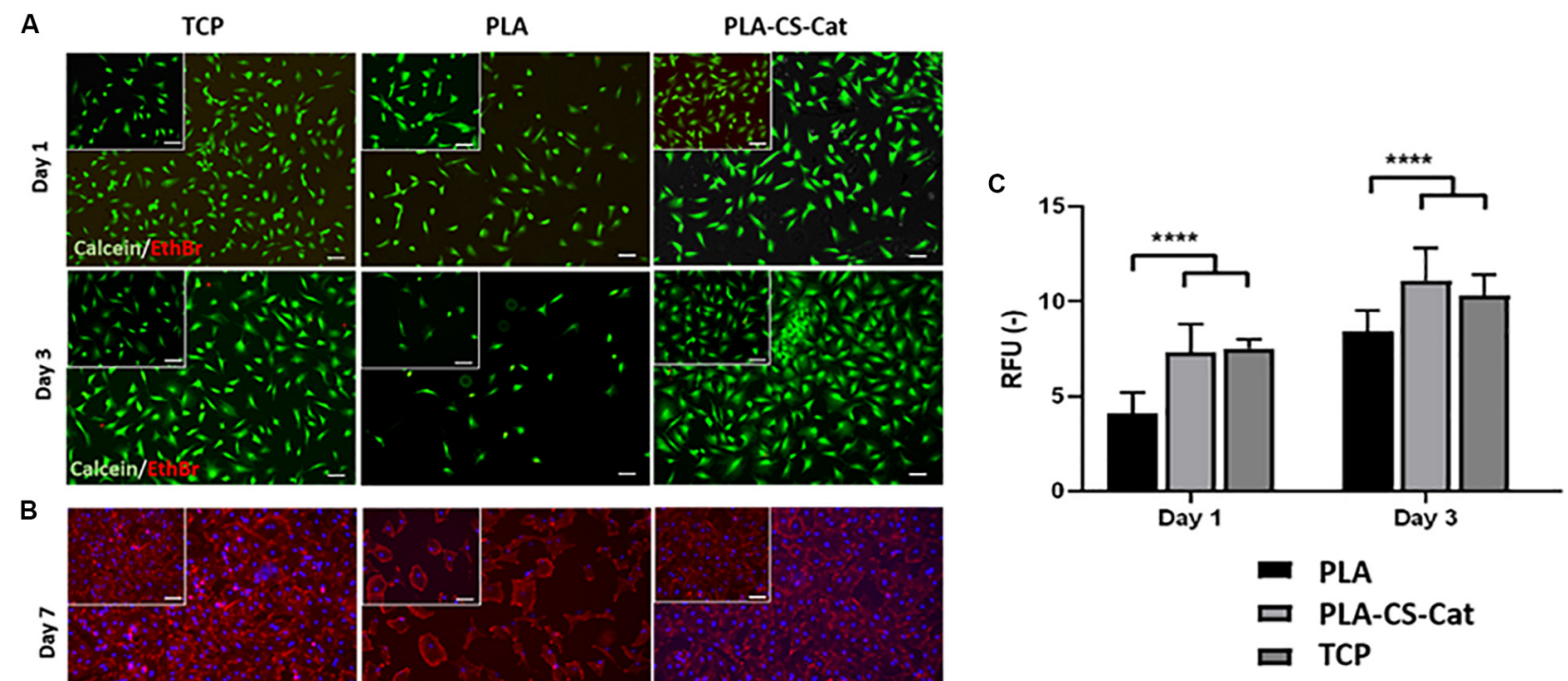

FIGURE 6 | (A) Live/Dead images at day 1 and day 3 for the TCP, PLA, and CS-Cat coated PLA samples: Ethidium bromide (EthBr) stains dead cells (red) and calcein stains live cells (green). (B) Immunostaining assay images at day 7 for the TCP, PLA, and PLA-CS-Cat substrates: DAPI stains nuclei (blue) and Phalloidin stains the cytoskeleton (red). (C) Prestoblue test to assess cells metabolic activity at day 1 and day 3 in all the three samples (PLA, PLA-CS-Cat, and TCP). Bars: $100 \mu \mathrm{m}$. Statistics: ${ }^{\star * *} p<0.0001$.

to $31.4^{\circ} \pm 2.9^{\circ}$ ), and $\mathrm{TiO}_{2}$ (from $73.7^{\circ} \pm 1.3^{\circ}$ to $16.3^{\circ} \pm 1.1^{\circ}$ ) (Figure 5B).

\section{Biological Assessment: Cells Viability, Metabolic Activity, and Morphology Onto the Substrates}

Live/Dead staining assay highlighted cell viability after 1 and 3 days of incubation on the CS-Cat coated PLA substrates (Figure 6A). All the samples showed a predominance of live cells (green) compared to dead cells (red) at both time points; moreover, the number of cells in the TCP and PLA-CS-Cat was higher compared to the PLA bare sample. The nuclei (DAPI) and cytoskeleton (Phalloidin) immunostaining test (Figure 6B) confirmed this statement: onto the PLA-CS-Cat samples, a higher percentage of cells was detected after 7 days concerning the PLA substrate and comparable with the TCP. Cells were assuming a spread shape on all the substrates. The PrestoBlue assay 
A

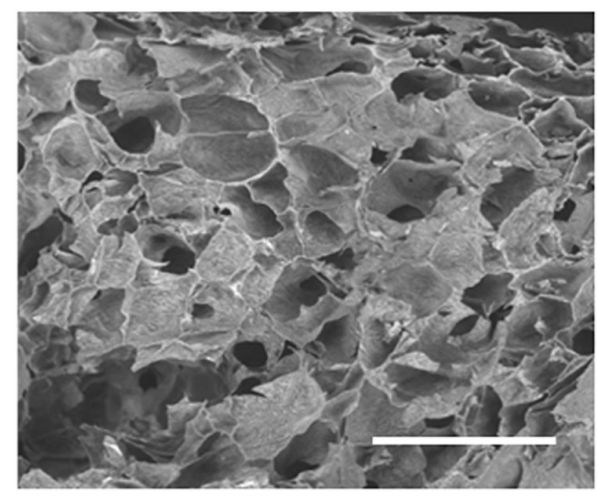

B

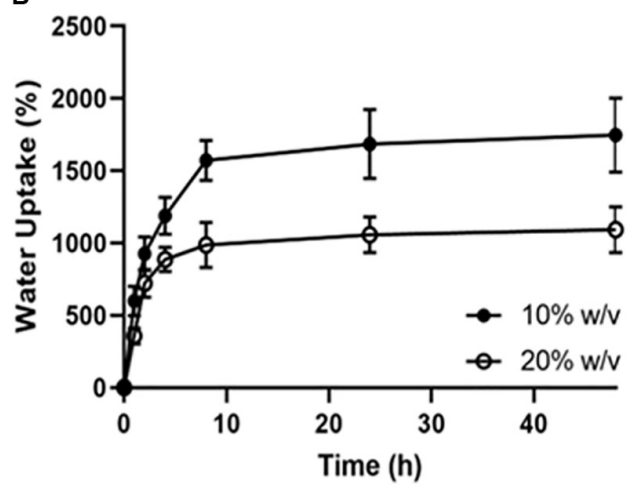

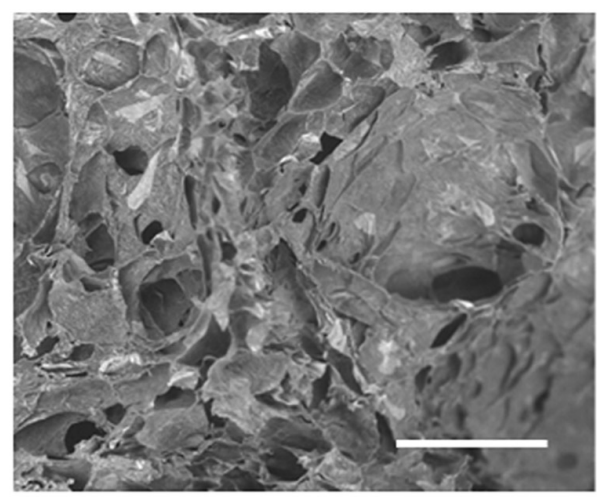

C

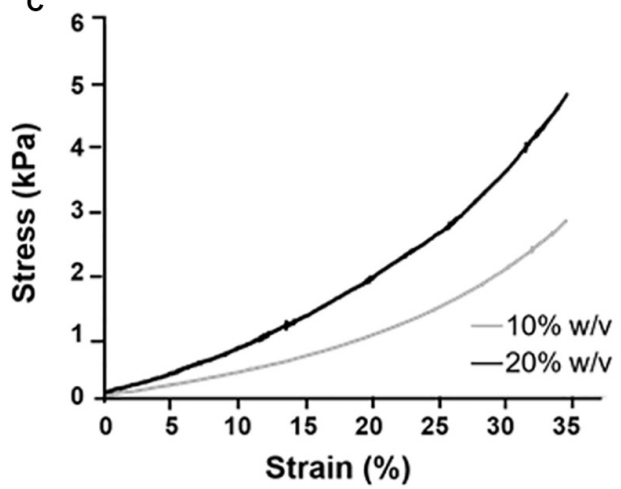

FIGURE 7 | Physico-chemical characterization of CS-Cat hydrogels: (A) SEM images of the lyophilised CS-Cat hydrogels: on the left 10\% CS-Cat and the right 20\% CS-Cat. Bars $=500 \mu \mathrm{m}$. (B) Water uptake study of CS-Cat at different time points for the 10\% (w/v) and 20\% (w/v) concentrations. (C) Undefined compression test: stress/strain $(\sigma / \varepsilon)$ curves for $10 \%(\mathrm{w} / \mathrm{v})$ and $20 \%(\mathrm{w} / \mathrm{v})$ CS-Cat hydrogels.

demonstrated that, from day 1 to 3 , Y201s metabolic activity increased in all the samples (Figure 6C). Interestingly, cells on coated PLA substrate and TCP showed a significant higher $(p<0.0001)$ metabolic activity compared to the bare PLA substrate at each time point.

\section{CS-Cat as Cohesive Hydrogel}

\section{Physico-Chemical and Mechanical Characterization}

In the presence of an oxidizing agent, sodium periodate in alkaline condition ( $\mathrm{pH} 8-9$ ), the CS-Cat solution instantly became gel by the chemical crosslinking between the conjugated Cat moieties. Particularly, we found that when the amount of sodium periodate was equivalents to the molar amount of Cat led to a complete gelation in $10 \mathrm{~min}$, while when the $\mathrm{NaIO}_{4} / \mathrm{Cat}$ stoichiometric ratio was 2:1 we found an immediate gelation that allowed several difficulties to pour the gel in appropriate vial or wells for the following characterization. Therefore, with a molar ratio of $1.5: 1$ the CS-Cat $(10 \% \mathrm{w} / \mathrm{v})$ became a gel in $50-60 \mathrm{~s}$ and CS-Cat $(20 \% \mathrm{w} / \mathrm{v})$ in less than $30 \mathrm{~s}$ and both time were suitable for handling the solutions.

The porous structure and pore size of the obtained hydrogels were examined by SEM after the freeze-drying (Figure 7A). The average pore size calculated by using ImageJ software was $\sim 140 \pm 67 \mu \mathrm{m}$ for the $10 \%$ (w/v) CS-Cat, while the $20 \%(\mathrm{w} / \mathrm{v}$ ) showed a non-statistically decrease $(\sim 93 \pm 58 \mu \mathrm{m})$.
The WU ability of the CS-Cat hydrogels is shown in Figure 7B. The samples displayed a fast increase of WU, reaching the values of $1571 \pm 139 \%$ for the $10 \%(\mathrm{w} / \mathrm{v})$ and $987 \pm 157 \%$ for the $20 \%$ $(\mathrm{w} / \mathrm{v})$ within $10 \mathrm{~h}$. Then, the WU percentage slowly increased and stabilized at $48 \mathrm{~h}$ at the values of $1747 \pm 257 \%$ for the $10 \%(\mathrm{w} / \mathrm{v})$ and $1092 \pm 159 \%$ for the $20 \%(\mathrm{w} / \mathrm{v})$.

Figure 7C shows the stress/strain curves for the two concentration of CS-Cat hydrogel tested. Under static compression, it was calculated the compressive elastic Young's modulus in the linear regions of both curves (0-10\% strain). The values obtained were: $4.6 \pm 1.8 \mathrm{kPa}$ for the $10 \% \mathrm{CS}$-Cat and $7.8 \pm 1.0 \mathrm{kPa}$ for the $20 \%$ CS-Cat.

Due to the lower WU degree and higher mechanical properties, the $20 \%(\mathrm{w} / \mathrm{v})$ CS-Cat hydrogel was selected for the further tests. Furthermore, the in vitro degradation behavior of 10 and $20 \% \mathrm{w} / \mathrm{v}$ samples was also studied (Supplementary Figure S2).

\section{CS-Cat as Hydrogels for Hosting Cells: Cells Viability, Morphology, and Metabolic Activity}

The Live/Dead staining showed that the Y201 cells encapsulated within the $20 \%$ CS-Cat hydrogels were viable (green) and characterized by round-like morphology (Figure 8A) at day 1 and day 3 of culture. Few dead (red) cells were found. Cells metabolic activity slightly decreased from day 1 to day $7(p<0.05)$ as shown 


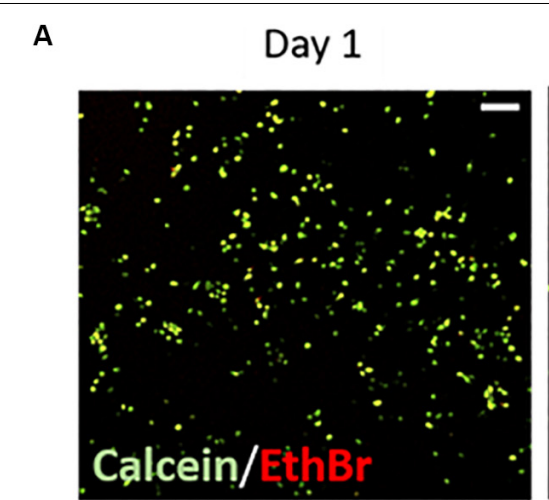

C

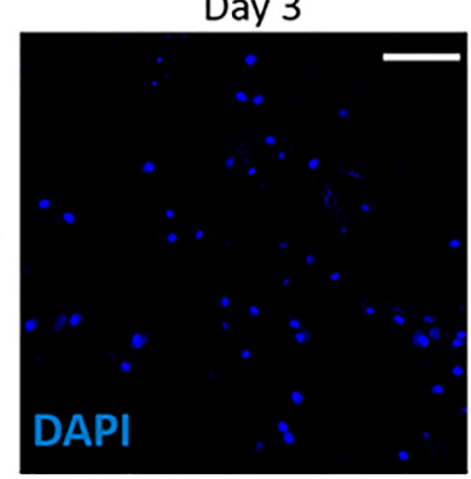

Day 3

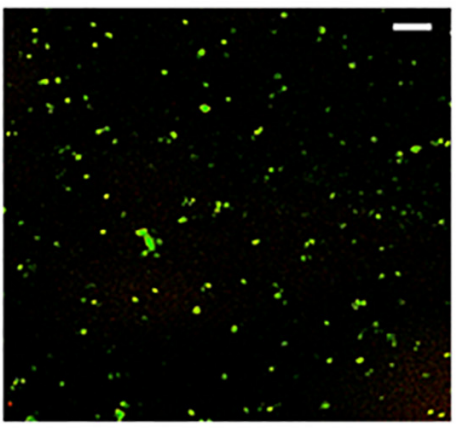

Day 7

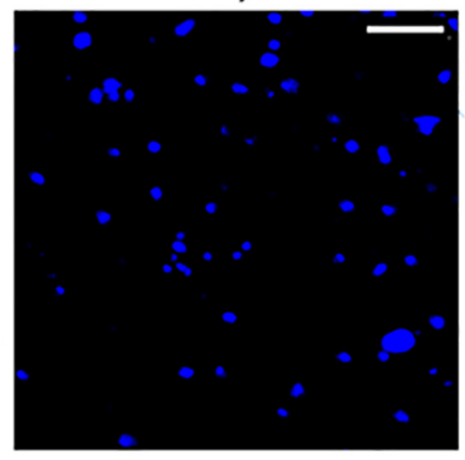

B

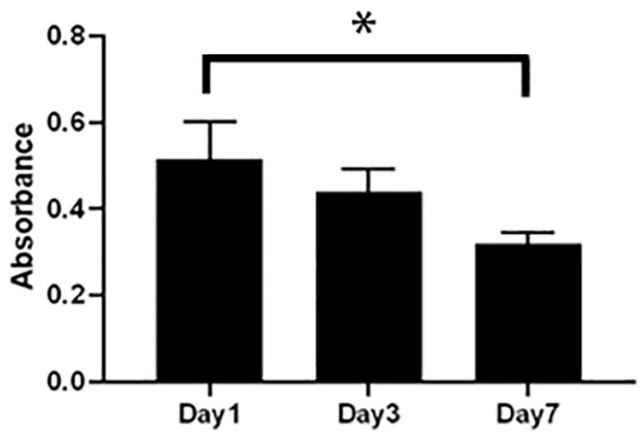

FIGURE 8 | (A) Live/Dead test to assess the cytotoxicity of the CS-Cat hydrogel. Live cells are stained in green (calcein) and dead cells in red (ethidium bromide). Bar $=100 \mu \mathrm{m}$. (B) Alamar blue test results showing cells metabolic activity within the hydrogel upon to 7 days. (C) Immunostaining images taken after 3 and 7 days of culture: nuclei are stained in blue (DAPI). Bar $=200 \mu \mathrm{m}$. Statistics: ${ }^{*} p<0.05$.

in Figure 8B. Finally, immunostaining analysis (nuclei stained with blue DAPI) showed the cells tend to agglomerate during the culture time Figure 8C.

\section{DISCUSSION}

In this work, we developed a biopolymers-based formulation composed of CS, a sulfated GAG made by an alternating sugars chain ( $N$-acetylgalactosamine and glucuronic acid) that generally comes from animal cartilage and DP, an organic chemical of the catecholamine and phenethylamine families, synthesized in plants and most animals (Zhu et al., 2019). Sodium periodate is an inorganic salt, composed of a sodium cation and the periodate anions and it is used for the crosslinking the conjugated CS-Cat. In particular, the Cat shows adhesive function in acidic condition, resulting in surface coating, while basic $\mathrm{pH}$ allows to enhance its cohesive properties, resulting in the formation of hydrogels (Saiz-Poseu et al., 2019).

The CS-Cat macromer was manufactured through a single step coupling reaction between the carboxyl groups from CS and the amine group from DP. Considering that the CS is a linear hetero-polysaccharide and holds repeating disaccharide units of glucuronic acid and galactosamine, enough carboxyl groups could be involved in the reaction. The reaction was performed in quite mild conditions without the addition of any organic or toxic reagent during the synthesis. Then, the solution obtained was dialysed against distilled water for a few days and freeze-dried; the obtained powders should be non-toxic. NMR spectra reported in Figure 3 revealed the presence of the multi-peaks related with the addition of the chemical DP groups onto the CS backbone; furthermore, a small amount of engrafted NHS residue was detected. From recent works, the NHS presence was introduced as a functional group in some bioadhesive formulations to assist the adhesion between the adhesive formulations and the biological surfaces (Strehin et al., 2010). Therefore, in the newly developed CS-Cat biomaterial, a tiny amount of NHS residue within the CS-Cat macromers can be considered acceptable.

Few conclusions relevant to the DP grafting could be obtained from the comparison of the C1s spectra, since the new bond formed between CS and DP was an amidic bond, still present on CS (Figure 4). Moreover, the possible residue presence of NHS may further complicate the curve fitting interpretation. Indeed, the amide groups in the NHS moieties were expected to fall at binding energies similar to the carboxyl groups rather than to the typical amide binding energies, probably due to the strain in the five-membered ring and the electron conjugation in the $\mathrm{N}$-succinimidyl esters, as reported in the literature (Cheng et al., 2007). In this scenario, the grafting of DP to CS may improve the peak at $287.9 \mathrm{eV}$, while the residue presence of bonded NHS may enrich the peak at $288.9 \mathrm{eV}$, making impossible an undoubtedly interpretation to the fitting results. On the other hand, the fitting 
of nitrogen signals supplied evidence of the DP grafting on the $\mathrm{CS}$ backbone. Indeed, subtracting the contribution at higher $\mathrm{BE}$ of CS-Cat N1s curve fitting to the total nitrogen percentage, the $\mathrm{N} / \mathrm{S}$ corrected peak area ratio in CS-Cat resulted equal to 3.5:1. In pure CS, this ratio was 2.6:1. The increase of this ratio can be directly ascribed to the formation of new amide groups between CS and DP, since both the free DP and the NHS contributions to the nitrogen have been excluded.

Hong et al. (2014) reported that facile surface modification of a variety of substrates in acidic condition could be obtained by Cat-functionalised biomaterial thanks to their adhesive properties. The synthesized CS-Cat exhibited an outstanding bio-adhesive property on different substrates at low $\mathrm{pH}$. Figure 5 evidences the significant decrease of the contact angle of the different substrates after being coated, by spincoating with the bioadhesive CS-Cat solution exhibiting a static contact angle $<35^{\circ}$. In our work, it is noticeable that most functionalized surfaces showed very hydrophilic properties and some substrates, i.e., $\mathrm{SiO}_{2}$ and $\mathrm{TiO}_{2}$ evidenced superhydrophilic properties, where nearly $100 \%$ of the surface was covered by the immobilized CS-Cat. As reported, other materials, such as PCL and PLA, showed a contact angle close to $30^{\circ}$. These results might represent partial surface modification as reported also by Hong et al. (2013), where they coated different polymeric, metallic, and ceramic substrates with HA conjugated chemically with DP. Furthermore, in order to evaluate the bonding strength of the Cat-based polymers on different substrates, it is proved that 3,4-dihydroxyphenylalanine in adhesive proteins, secreted by marine mussels, plays an important role in interfacial binding and intermolecular crosslinking (Lee et al., 2011). It was reported also that Cat could form strong and reversible bonds with metal oxides reaching $40 \%$ of covalent bond strength, the strongest reversible bond involving a biological molecule reported to date. Furthermore, as reported by Lih et al. (2016), natural polymer-Cat conjugates, when coated, start first to be self-assembled and aggregated due to relatively balanced hydrophilic (natural polymer) and hydrophobic (DP) segments, followed by $\pi-\pi$ stacking of aromatic rings in Cat and, lastly, characterized by selfpolymerisation of DP. Hovewer, the Cat amount conjugated to polymeric chain and the manufacturing method used for the coating preparation can affect the bonding strength on the substrate.

The wettability/hydrophilicity degree of the substrate surfaces strongly influence the cells adhesion and spreading with an enhanced biological behavior on hydrophilic surfaces compared to the hydrophobic ones. This is reported by several researchers (Webb et al., 1998; Dowling et al., 2011; Dave and Gomes, 2019). Among the hydrophilic surfaces, cells attachment resulted to be influenced by substrates charge and wettability, while cell area, shape, or cytoskeletal organization did not result to be affected by these properties. Surfaces with a moderate hydrophilicity $\left(20-40^{\circ}\right.$ water contact angle) resulted to highly promote cells attachment. This was confirmed in our work; in fact, the Live/Dead assay showed good cells viability with few dead cells at both time points, meaning that the culture conditions did not present cytotoxic effect. Despite the Y201 showed viability even on the PLA substrate, the CS-Cat coated PLA samples showed a higher ability to promote cell attachment, spreading, proliferation and metabolic activity, compared to the PLA bare substrate (Figure 6). Indeed, Live/Dead and immunostaining assay images demonstrated that cells were spread and homogeneously distributed along all the CS-Cat coated PLA substrate surface, as well as on the TCP substrate, compared to the hydrophobic PLA uncoated substrate (Figures 6A,B). In addition, Y201 metabolic activity was higher for the PLA-CS-Cat sample compared to the PLA, confirming the fact that this hydrophilic environment is very suitable for cells (Figure 6C).

In addition to the bio-adhesive properties, CS-Cat biomaterial can assume cohesive properties under basic conditions $(\mathrm{pH}>8)$. Upon the addition of the $\mathrm{NaIO}_{4}$, the solution became gel in less than a minute. The same cohesive behavior has been exhibited by other types of hydrogels, i.e., polyethylene glycol (PEG)-based gels (Kaneko et al., 2010), in which the deprotonation of the hydroxyl groups in Cat produces the quinone, resulting in cohesive crosslinking reactions (Liu et al., 2006; Hong et al., 2014). Opposite to other reported PEG- Cat hydrogels where multi-arm branched PEGs were primarily utilized to make the sol-gel transition, the formation of hydrogels by using linear polymeric chain arrangement is extremely more challenging, because physical cross-linking of polymer chains can be achieved with several environmental triggers, i.e., temperature, $\mathrm{pH}$ and ionic strength, and physicochemical interactions, i.e., hydrophobic, hydrogen bonding, or supramolecular chemistry (Hoare and Kohane, 2008). The first successful work on using natural polymers with this structure has been reported in Hong et al. (2013) where the authors reported the chemical conjugation of HA-Cat via carbodiimide coupling reaction.

The WU is a significant property of a crosslinked hydrogel, especially if the gel is proposed to be used as a bioadhesive in an internal environment. If the WU of a hydrogelderived bio-adhesive is elevated, it may embrace an excessive amount of water content from the surrounding tissues and this may cause severe pressure on the surrounding tissues (Spicer, 2020). In this work, we tested two concentrations $[10 \%(\mathrm{w} / \mathrm{v})$ and $20 \%(\mathrm{w} / \mathrm{v})]$. The WU test for the $20 \%$ $(w / v)$ formulation proved the CS-Cat hydrogel to have a hydrophilic nature, with the ability to hold water molecules, remaining stable (Figure 7B). Furthermore, in terms of mechanical properties, the compression test demonstrated that both the CS-Cat formulations exhibit a Young's modulus value $<10 \mathrm{kPa}$ (Figure 7C). In particular, the 20\% (w/v) hydrogel evidenced a higher $\mathrm{E}(\sim 8 \mathrm{kPa})$ compared to the $10 \%$ $(\mathrm{w} / \mathrm{v})$ hydrogel $(\mathrm{E} \sim 5 \mathrm{kPa})$. Both values could be considered suitable for hydrogels intended for soft tissue engineering application, i.e., musculoskeletal (Park H. et al., 2013; Liu et al., 2020), pancreatic (Montalbano et al., 2018), and vascular (Liu et al., 2015) applications. From the obtained enhanced physicochemical and mechanical results, we decided to select the $20 \%(\mathrm{w} / \mathrm{v})$ concentration to perform the biological tests; indeed, this formulation showed good cell affinity when cells were encapsulated within it. In fact, it presented good properties in terms of cells viability as demonstrated by the 
Live/Dead assay (Figure 8A) and nuclei integrity (stained with DAPI; Figure 8C). Regarding the Alamar blue assay (Figure 8B), it has been observed a decrease in cells metabolic activity at day 7 of culture. This behavior could be explained considering that, when onto a 2D surface, MSCs are in a proliferative state, which involves a mixed metabolism (glycolysis and oxidative phosphorylation), while within a $3 \mathrm{D}$ environment higher rates of glycolysis and a suppression of oxidative phosphorylation are showed due cells shift to differentiation state (Pattappa et al., 2011). This mechanism is influenced by the presence of low oxygen tension which activates the hypoxia-inducible factor (HIF) mediated pathway (Liu and Ma, 2015). Therefore, this may occur in this change of metabolic state of cells within the CS-Cat hydrogel after 7 days of culture.

\section{CONCLUSION}

A novel CS-Cat biomaterial has been successfully engineered with bio-adhesiveness and cohesiveness properties at different conditions suitable for regenerative medicine, demonstrating excellent cytocompatibility assessed by Y201 cells. The CS-Cat formulation as bio-adhesive showed to improve considerably the hydrophilicity properties of different substrates, with a potential use in diverse conditions during clinical operations, such as for coating orthopedic implants. Furthermore, due to its cohesive properties at high $\mathrm{pH}$ and its ability to undergo a sol/gel transition in less than $60 \mathrm{~s}$ with an intrinsic porous structure, the CS-Cat formulation has also prospects for being used as a bioink for future bioprinting applications for tissue regeneration (i.e., cartilage tissue), alone or as a hybrid bioformulation in combination with fillers to obtain increased mechanical properties.

\section{REFERENCES}

Brennan, M. J., Meredith, H. J., Jenkins, C. L., Wilker, J. J., and Liu, J. C. (2016). Cytocompatibility studies of a biomimetic copolymer with simplified structure and high-strength adhesion. J. Biomed. Mater. Res. A 104, 983-990. doi: 10. 1002/jbm.a.35633

Chen, S.-M., and Peng, K.-T. (2003). The electrochemical properties of dopamine, epinephrine, norepinephrine, and their electrocatalytic reactions on cobalt (II) hexacyanoferrate films. J. Electroanal. Chem. 547, 179-189. doi: 10.1016/s00220728(03)00220- 1

Cheng, F., Gamble, L. J., Grainger, D. W., and Castner, D. G. (2007). X-ray photoelectron spectroscopy, time-of-flight secondary ion mass spectrometry, and principal component analysis of the hydrolysis, regeneration, and reactivity of N-hydroxysuccinimide-containing organic thin films. Anal. Chem. 79, 87818788. doi: $10.1021 / \mathrm{ac} 0715423$

Dave, K., and Gomes, V. G. (2019). Interactions at scaffold interfaces: effect of surface chemistry, structural attributes and bioaffinity. Mater. Sci. Eng. C 105:110078. doi: 10.1016/j.msec.2019.110078

Dowling, D. P., Miller, I. S., Ardhaoui, M., and Gallagher, W. M. (2011). Effect of surface wettability and topography on the adhesion of osteosarcoma cells on plasma-modified polystyrene. J. Biomater. Appl. 26, 327-347. doi: 10.1177/ 0885328210372148

Farrugia, B., Lord, M., Whitelock, J., and Melrose, J. (2018). Harnessing chondroitin sulphate in composite scaffolds to direct progenitor and stem cell function for tissue repair. Biomater. Sci. 6, 947-957. doi: 10.1039/c7bm $01158 \mathrm{j}$

\section{DATA AVAILABILITY STATEMENT}

Data supporting this publication are openly available under an "Open Data Commons Open Database License." Additional metadata are available at: http://dx.doi.org/10.25405/data.ncl. 12102666. Please contact Newcastle Research Data Service at rdm@ncl.ac.uk for access instructions.

\section{AUTHOR CONTRIBUTIONS}

AF and PG conceived the study. AF, ED, and PG designed the experiments. AF, AS, MB, and PG optimized the CSCat formulation. ED and SC performed the XPS analysis. FC performed the NMR and UV-Vis analyses. AS performed the mechanical properties. AS and MB performed the in vitro cell tests. All the authors analyzed and interpreted the data and prepared the manuscript.

\section{FUNDING}

AS acknowledges support from EPSRC for her Ph.D. studentship (EPSRC Grant EP/R51309X/1). The authors thank Mr. M. Foster for SEM images (School of Engineering, Newcastle University) and Dr. R. Ribeiro-Conceicao for the preliminary in vitro cell experiments.

\section{SUPPLEMENTARY MATERIAL}

The Supplementary Material for this article can be found online at: https://www.frontiersin.org/articles/10.3389/fbioe. 2020.00712/full\#supplementary-material

Han, L., Wang, M., Li, P., Gan, D., Yan, L., Xu, J., et al. (2018). Musselinspired tissue-adhesive hydrogel based on the polydopamine-chondroitin sulfate complex for growth-factor-free cartilage regeneration. ACS Appl. Mater. Interfaces 10, 28015-28026. doi: 10.1021/acsami.8b05314

Hoare, T. R., and Kohane, D. S. (2008). Hydrogels in drug delivery: progress and challenges. Polymer 49, 1993-2007. doi: 10.1016/j.polymer.2008. 01.027

Hong, S., Lee, H., and Lee, H. (2014). Controlling mechanical properties of bio-inspired hydrogels by modulating nano-scale, inter-polymeric junctions. Beilstein J. Nanotechnol. 5, 887-894. doi: 10.3762/bjnano.5.101

Hong, S., Yang, K., Kang, B., Lee, C., Song, I. T., Byun, E., et al. (2013). Hyaluronic acid catechol: a biopolymer exhibiting a pH-dependent adhesive or cohesive property for human neural stem cell engineering. Adv. Funct. Mater. 23, 1774-1780. doi: 10.1002/adfm.201202365

Imperiale, A., Moussallieh, F.-M., Sebag, F., Brunaud, L., Barlier, A., Elbayed, K., et al. (2013). A new specific succinate-glutamate metabolomic hallmark in SDHx-related paragangliomas. PLoS One 8:e80539. doi: 10.1371/journal.pone. 0080539

James, S., Fox, J., Afsari, F., Lee, J., Clough, S., Knight, C., et al. (2015). Multiparameter analysis of human bone marrow stromal cells identifies distinct immunomodulatory and differentiation-competent subtypes. Stem Cell Rep. 4, 1004-1015. doi: 10.1016/j.stemcr.2015.05.005

Joo, H., Byun, E., Lee, M., Hong, Y., Lee, H., and Kim, P. (2016). Biofunctionalization via flow shear stress resistant adhesive polysaccharide, hyaluronic acid-catechol, for enhanced in vitro endothelialization. J. Ind. Eng. Chem. 34, 14-20. doi: 10.1016/j.jiec.2015.11.015 
Kaneko, D., Kinugawa, S., Matsumoto, K., and Kaneko, T. (2010). Terminallycatecholized hyper-branched polymers with high performance adhesive characteristics. Plant Biotechnol. 27, 293-296. doi: 10.5511/plantbiotechnology. 27.293

Kim, K., Kim, K., Ryu, J. H., and Lee, H. (2015). Chitosan-catechol: a polymer with long-lasting mucoadhesive properties. Biomaterials 52, 161-170. doi: 10.1016/ j.biomaterials.2015.02.010

Kim, K., Ryu, J. H., Lee, D. Y., and Lee, H. (2013). Bio-inspired catechol conjugation converts water-insoluble chitosan into a highly water-soluble, adhesive chitosan derivative for hydrogels and LbL assembly. Biomater. Sci. 1, 783-790.

Krogsgaard, M., Behrens, M. A., Pedersen, J. S., and Birkedal, H. (2013). Selfhealing mussel-inspired multi-pH-responsive hydrogels. Biomacromolecules 14, 297-301. doi: 10.1021/bm301844u

Lee, B. P., Messersmith, P. B., Israelachvili, J. N., and Waite, J. H. (2011). Musselinspired adhesives and coatings. Annu. Rev. Mater. Res. 41, 99-132.

Lee, C., Shin, J., Lee, J. S., Byun, E., Ryu, J. H., Um, S. H., et al. (2013). Bioinspired, calcium-free alginate hydrogels with tunable physical and mechanical properties and improved biocompatibility. Biomacromolecules 14, 2004-2013. doi: 10.1021/bm400352d

Lee, H., Lee, B. P., and Messersmith, P. B. (2007). A reversible wet/dry adhesive inspired by mussels and geckos. Nature 448:338. doi: 10.1038/nature05968

Lee, H., Lee, K. D., Pyo, K. B., Park, S. Y., and Lee, H. (2010). Catechol-grafted poly (ethylene glycol) for PEGylation on versatile substrates. Langmuir 26, 3790-3793. doi: 10.1021/la904909h

Lih, E., Choi, S. G., Ahn, D. J., Joung, Y. K., and Han, D. K. (2016). Optimal conjugation of catechol group onto hyaluronic acid in coronary stent substrate coating for the prevention of restenosis. J. Tissue Eng. 7:2041731416683745.

Lingor, P., Teusch, N., Schwarz, K., Mueller, R., Mack, H., Bähr, M., et al. (2007). Inhibition of Rho kinase (ROCK) increases neurite outgrowth on chondroitin sulphate proteoglycan in vitro and axonal regeneration in the adult optic nerve in vivo. J. Neurochem. 103, 181-189.

Liu, J., Yang, B., Li, M., Li, J., and Wan, Y. (2020). Enhanced dual network hydrogels consisting of thiolated chitosan and silk fibroin for cartilage tissue engineering. Carbohydr. Polymers 227:115335. doi: 10.1016/j.carbpol.2019.115335

Liu, J., Zheng, H., Poh, P. S., Machens, H.-G., and Schilling, A. F. (2015). Hydrogels for engineering of perfusable vascular networks. Int. J. Mol. Sci. 16, 1599716016. doi: 10.3390/ijms160715997

Liu, M., Zeng, X., Ma, C., Yi, H., Ali, Z., Mou, X., et al. (2017). Injectable hydrogels for cartilage and bone tissue engineering. Bone Res. 5, 1-20.

Liu, Y., and Ma, T. (2015). Metabolic regulation of mesenchymal stem cell in expansion and therapeutic application. Biotechnol. Prog. 31, 468-481. doi: $10.1002 /$ btpr.2034

Liu, Z., Wasmuth, A. S., and Nelson, S. G. (2006). Au (I)-catalyzed annulation of enantioenriched allenes in the enantioselective total synthesis of (-)-rhazinilam. J. Am. Chem. Soc. 128, 10352-10353. doi: 10.1021/ja0629110

Marcelo, G., LoìPez-Gonzailez, M., Mendicuti, F., Tarazona, M. P., and Valiente, M. (2014). Poly (N-isopropylacrylamide)/gold hybrid hydrogels prepared by catechol redox chemistry. Characterization and smart tunable catalytic activity. Macromolecules 47, 6028-6036. doi: 10.1021/ma501214k

Matos-Pérez, C. R., White, J. D., and Wilker, J. J. (2012). Polymer composition and substrate influences on the adhesive bonding of a biomimetic, crosslinking polymer. J. Am. Chem. Soc. 134, 9498-9505. doi: 10.1021/ja303 $369 p$

Montalbano, G., Toumpaniari, S., Popov, A., Duan, P., Chen, J., Dalgarno, K., et al. (2018). Synthesis of bioinspired collagen/alginate/fibrin based hydrogels for soft tissue engineering. Mater. Sci. Eng. C 91, 236-246. doi: 10.1016/j.msec.2018.04. 101

Montell, E., Contreras-Muñoz, P., Torrent, A., Vergés, J., De La Varga, M., Rodas, G., et al. (2017). Chondroitin sulfate and glucosamine combination treatment for musculoskeletal diseases and osteoarthritis: a chance to kill two birds with one stone? results in a rat injury model. Osteoarthr. Cartil. 25, S367-S368.

Neto, A. I., Cibrão, A. C., Correia, C. R., Carvalho, R. R., Luz, G. M., Ferrer, G. G., et al. (2014). Nanostructured polymeric coatings based on chitosan and dopamine-modified hyaluronic acid for biomedical applications. Small 10, 2459-2469. doi: 10.1002/smll.201303568
Park, H., Choi, B., Hu, J., and Lee, M. (2013). Injectable chitosan hyaluronic acid hydrogels for cartilage tissue engineering. Acta Biomater. 9, 4779-4786. doi: 10.1016/j.actbio.2012.08.033

Park, J. Y., Kim, J. S., and Nam, Y. S. (2013). Mussel-inspired modification of dextran for protein-resistant coatings of titanium oxide. Carbohydr. Polymers 97, 753-757. doi: 10.1016/j.carbpol.2013.05.064

Pattappa, G., Heywood, H. K., De Bruijn, J. D., and Lee, D. A. (2011). The metabolism of human mesenchymal stem cells during proliferation and differentiation. J. Cell. Physiol. 226, 2562-2570. doi: 10.1002/jcp. 22605

Ryu, J. H., Hong, S., and Lee, H. (2015). Bio-inspired adhesive catechol-conjugated chitosan for biomedical applications: a mini review. Acta biomaterialia 27, 101-115. doi: 10.1016/j.actbio.2015.08.043

Ryu, J. H., Lee, Y., Kong, W. H., Kim, T. G., Park, T. G., and Lee, H. (2011) Catechol-functionalized chitosan/pluronic hydrogels for tissue adhesives and hemostatic materials. Biomacromolecules 12, 2653-2659. doi: 10.1021/ bm200464x

Saiz-Poseu, J., Mancebo-Aracil, J., Nador, F., Busqué, F., and Ruiz-Molina, D. (2019). The chemistry behind catechol-based adhesion. Angew. Chem. Int. Ed. 58, 696-714. doi: 10.1002/anie.201801063

Salbach, J., Rachner, T. D., Rauner, M., Hempel, U., Anderegg, U., Franz, S., et al. (2012). Regenerative potential of glycosaminoglycans for skin and bone. J. Mol. Med. 90, 625-635. doi: 10.1007/s00109-011-0843-2

Scalzone, A., Ferreira, A. M., Tonda-Turo, C., Ciardelli, G., Dalgarno, K., and Gentile, P. (2019). The interplay between chondrocyte spheroids and mesenchymal stem cells boosts cartilage regeneration within a $3 \mathrm{D}$ natural-based hydrogel. Sci. Rep. 9, 1-12.

Shin, J., Lee, J. S., Lee, C., Park, H. J., Yang, K., Jin, Y., et al. (2015). Tissue adhesive catechol-modified hyaluronic acid hydrogel for effective, minimally invasive cell therapy. Adv. Funct. Mater. 25, 3814-3824. doi: 10.1002/adfm.20150 0006

Son, H. Y., Ryu, J. H., Lee, H., and Nam, Y. S. (2013). Bioinspired templating synthesis of metal-polymer hybrid nanostructures within 3D electrospun nanofibers. ACS Appl. Mater. Interfaces 5, 6381-6390. doi: 10.1021/am40 $1550 \mathrm{p}$

Spicer, C. D. (2020). Hydrogel scaffolds for tissue engineering: the importance of polymer choice. Polymer Chem. 2013, 316-342.

Strehin, I., Nahas, Z., Arora, K., Nguyen, T., and Elisseeff, J. (2010) A versatile $\mathrm{pH}$ sensitive chondroitin sulfate-PEG tissue adhesive and hydrogel. Biomaterials 31, 2788-2797. doi: 10.1016/j.biomaterials.2009. 12.033

Toida, T., Toyoda, H., and Imanari, T. (1993). High-resolution proton nuclear magnetic resonance studies on chondroitin sulfates. Anal. Sci. 9, 53-58. doi: 10.2116/analsci.9.53

Üstün, B., Sanders, K., Dani, P., and Kellenbach, E. (2011). Quantification of chondroitin sulfate and dermatan sulfate in danaparoid sodium by $1 \mathrm{H} \mathrm{NMR}$ spectroscopy and PLS regression. Anal. Bioanal. Chem. 399, 629-634. doi: 10.1007/s00216-010-4193-7

Varghese, S., Hwang, N. S., Canver, A. C., Theprungsirikul, P., Lin, D. W., and Elisseeff, J. (2008). Chondroitin sulfate based niches for chondrogenic differentiation of mesenchymal stem cells. Matrix Biol. 27, 12-21. doi: 10.1016/ j.matbio.2007.07.002

Von Fraunhofer, J. A. (2012). Adhesion and cohesion. Int. J. Dent. 2012: 951324.

Waite, J. H., and Tanzer, M. L. (1981). Polyphenolic substance of Mytilus edulis: novel adhesive containing L-dopa and hydroxyproline. Science 212, 1038-1040. doi: $10.1126 /$ science.212.4498.1038

Webb, K., Hlady, V., and Tresco, P. A. (1998). Relative importance of surface wettability and charged functional groups on NIH 3T3 fibroblast attachment, spreading, and cytoskeletal organization. J. Biomed. Mater. Res. 41, 422-430. doi: 10.1002/(sici)1097-4636(19980905)41:3<422::aid-jbm12>3.0. co;2-k

Xie, C., Wang, X., He, H., Ding, Y., and Lu, X. (2020). Mussel-inspired hydrogels for self-adhesive bioelectronics. Adv. Funct. Mater. 2020:1909954. doi: 10.1002/ adfm.201909954

Xu, J., Strandman, S., Zhu, J. X. X., Barralet, J., and Cerruti, M. (2015). Genipincrosslinked catechol-chitosan mucoadhesive hydrogels for buccaldrug 
delivery. Biomaterials 37, 395-404. doi: 10.1016/j.biomaterials.2014. 10.024

Yang, J., Stuart, M. A. C., and Kamperman, M. (2014). Jack of all trades: versatile catechol crosslinking mechanisms. Chem. Soc. Rev. 43, 8271-8298. doi: 10 . $1039 / \mathrm{c} 4 \mathrm{cs} 00185 \mathrm{k}$

Yang, Y., Qi, P., Wen, F., Li, X., Xia, Q., Maitz, M. F., et al. (2014). Mussel-inspired one-step adherent coating rich in amine groups for covalent immobilization of heparin: hemocompatibility, growth behaviors of vascular cells, and tissue response. ACS Appl. Mater. Interfaces 6, 14608-14620. doi: 10.1021/am503 $925 \mathrm{r}$

Zhu, W., Iqbal, J., and Wang, D.-A. (2019). A DOPA-functionalized chondroitin sulfate-based adhesive hydrogel as a promising multi-functional bioadhesive. J. Mater. Chem. B 7, 1741-1752. doi: 10.1039/c8tb01990h
Conflict of Interest: SC was employed by company Jaber Innovation s.r.l.

The remaining authors declare that the research was conducted in the absence of any commercial or financial relationships that could be construed as a potential conflict of interest.

Copyright $\odot 2020$ Scalzone, Bonifacio, Cometa, Cucinotta, De Giglio, Ferreira and Gentile. This is an open-access article distributed under the terms of the Creative Commons Attribution License (CC BY). The use, distribution or reproduction in other forums is permitted, provided the original author(s) and the copyright owner(s) are credited and that the original publication in this journal is cited, in accordance with accepted academic practice. No use, distribution or reproduction is permitted which does not comply with these terms. 